\title{
S100A1: a Major Player in Cardiovascular Performance
}

\author{
S. DUARTE-COSTA ${ }^{1}$, R. CASTRO-FERREIRA ${ }^{1}$, J. S. NEVES ${ }^{1}$, A. F. LEITE-MOREIRA ${ }^{1,2}$ \\ ${ }^{1}$ Department of Physiology and Cardiothoracic Surgery, Faculty of Medicine, University of Porto, \\ Porto, Portugal, ${ }^{2}$ Department of Cardiothoracic Surgery, Centro Hospitalar São João, EPE, Porto, \\ Portugal
}

Received December 4, 2013

Accepted March 21, 2014

On-line August 26, 2014

\section{Summary}

Calcium cycling is a major determinant of cardiac function. S100A1 is the most abundant member of the calcium-binding S100 protein family in myocardial tissue. S100A1 interacts with a variety of calcium regulatory proteins such as SERCA2a, ryanodine receptors, L-type calcium channels and $\mathrm{Na}^{+} / \mathrm{Ca}^{2+}$ exchangers, thus enhancing calcium cycling. Aside from this major function, S100A1 has an important role in energy balance, myofilament sliding, myofilament calcium sensibility, titin-actin interaction, apoptosis and cardiac remodeling. Apart from its properties regarding cardiomyocytes, S100A1 is also important in vessel relaxation and angiogenesis. S100A1 potentiates cardiac function thus increasing the cardiomyocytes' functional reserve; this is an important feature in heart failure. In fact, S100A1 seems to normalize cardiac function after myocardial infarction. Also, S100A1 is essential in the acute response to adrenergic stimulation. Gene therapy experiments show promising results, although further studies are still needed to reach clinical practice. In this review, we aim to describe the molecular basis and regulatory function of $\mathrm{S} 100 \mathrm{~A} 1$, exploring its interactions with a myriad of target proteins. We also explore its functional effects on systolic and diastolic function as well as its acute actions. Finally, we discuss S100A1 gene therapy and its progression so far.

\section{Key words}

Heart failure $\bullet$ Calcium homeostasis $\bullet$ Contractile function $\bullet$ Gene therapy • Endothelial dysfunction

\section{Corresponding author}

A. Leite-Moreira, Department of Physiology and Cardiothoracic Surgery, Faculty of Medicine, University of Porto, Al. Prof.
Hernani Monteiro, 4200-319 Porto, Portugal. Fax: +351225513646. E-mail: amoreira@med.up.pt

\section{Introduction}

$\mathrm{S} 100 \mathrm{~A} 1$ is a protein of the S100 family that normally exists as a homodimer. S100 proteins are calcium-binding proteins which use calcium influx to control a variety of cellular processes such as contraction, apoptosis and gene expression (Wright et al. 2005). This protein was first isolated from bovine brain and called S100 due to its solubility in $100 \%$ saturated ammonium sulfate solution (Moore 1965). S100 genes are located in the 1q21 chromosome and were named with Arabic numbers (S100A1 to S100A16). Also, some gene products which are very similar to $\mathrm{S} 100 \mathrm{~A} 7$ were named S100A7L (S100 calcium binding protein A7-like). Other S100 genes located outside this locus were named with letters (S100B, S100G, S100P and S100Z). There are also S100 proteins which are the result of pseudogene products (Marenholz et al. 2004, Wright et al. 2009).

In response to calcium binding, $\mathrm{S} 100$ proteins change their conformation. A specific hydrophobic pocket is exposed in response to calcium binding (Drohat et al. 1998, Smith et al. 1998, Otterbein et al. 2002). This conformational change is known to activate most of the S100-target protein interactions (Drohat et al. 1998, Smith et al. 1998). The binding site of target proteins consists of residues from the hinge region, the helix 3 and the helix 4 . These residues have the highest heterogeneity, which explains the very specific action of the proteins of the S100 family (Wright et al. 2009). 
Calcium binding is of crucial importance to S100A1 activity. Post-transcriptional modifications can alter S100A1 affinity to calcium substantially. A remark should be made on the post-translational S-nitrosylation at the C-terminal Cys85 which appears to substantially increase S100A1's affinity to calcium. S-nitrosylation at the C-terminal Cys85 modifies the conformation of several portions of the S100A1 protein, including the hydrophobic core and the helices 2 and 3. S-nitrosylation may regulate $\mathrm{S} 100 \mathrm{~A} 1$ 's function by increasing its affinity to both calcium and target proteins. Nevertheless, the functional importance of S-nitrosylation is still unknown (Lenarcic Zivkovic et al. 2012).

\section{S100A1: interaction with target proteins and functional importance}

\section{S100A1 in normal and dysfunctional myocardium}

Heart failure (HF) is defined as a condition in which the heart muscle is unable to pump enough blood to meet the body's needs for nutrients and oxygen, or does so at increased ventricular filling pressures (Ventura-Clapier et al. 2004). This condition is still a major cause of both mortality and morbidity, alerting to the need of finding new treatment options (Roger et al. 2012).

S100A1 is abundantly present in myocardial tissue (Haimoto et al. 1988, Remppis et al. 1996) and has been shown to be distributed unevenly according to compartmental workload, with highest expression in the left ventricle (Remppis et al. 1996). Combined with the evidence that S100A1 mRNA and protein levels are diminished in failing cardiomyocytes (Remppis et al. 1996), this gave the first clues about its functional significance. Also, an inverse relationship between S100A1 levels and the severity of heart failure has been reported (Most et al. 2006). In fact, it appears that more than $50 \%$ of normal S100A1 protein levels are required to achieve normal cardiac function (Volkers et al. 2010, Rohde et al. 2011). S100A1 overexpression prevents the development of postischemic heart failure in mice cardiomyocytes and reduces mortality after myocardial infarction. Indeed, S100A1 has been shown to play a major role in improving cardiac function, mainly under hemodynamic stress (Du et al. 2002, Most et al. 2006) (Fig. 1). Impaired calcium cycling is one of the major causes underlying the pathophysiological development of heart failure (Lompre et al. 2010, Rohde et al. 2011). As will be discussed later, S100A1 is likely to have a pivotal role in calcium handling.

Endothelin-1 (ET-1) and phenylephrine through protein kinase $\mathrm{C}$ (PKC) regulation have been shown to diminish S100A1 mRNA levels. Therefore, increased levels of ET-1 and phenylephrine may contribute to the decrease in S100A1 levels observed in heart failure (Most et al. 2006).

S100A1 effects have been shown to be protein kinase A (PKA)-independent (Most et al. 2001, Lohse et al. 2003), so, theoretically, it should rule out most of the detrimental effects of long-term $\beta$-adrenergic action (Lohse et al. 2003). Indeed, there is no current information reporting maladaptive responses to increased levels of S100A1 protein.

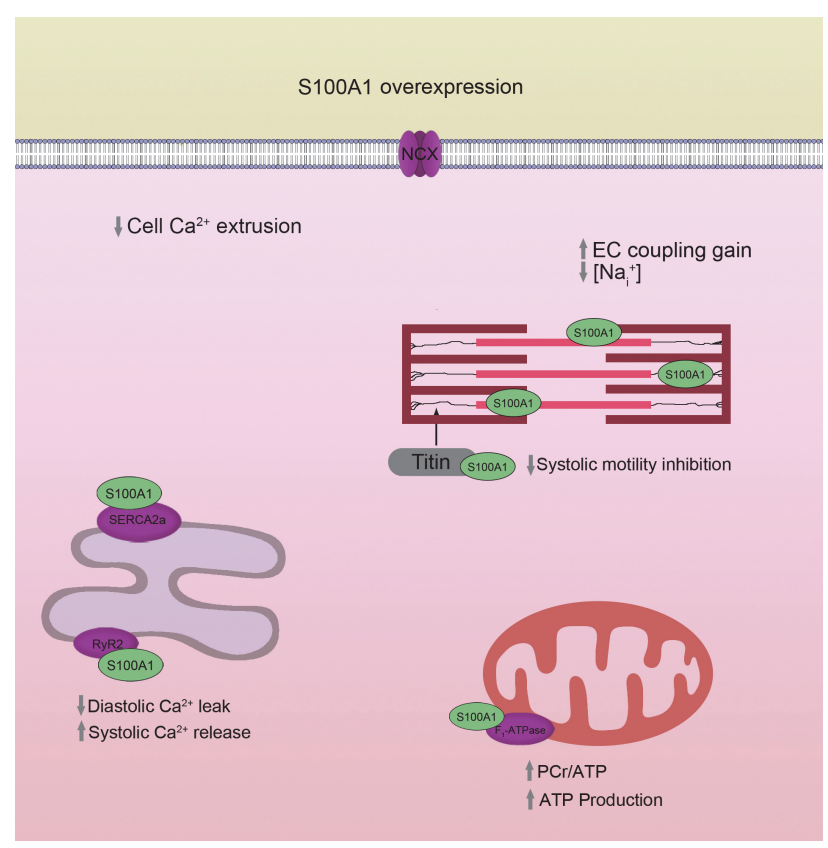

Fig. 1. Calcium ${ }^{+}$and energy homeostasis and titin determined passive tension in S100A1 overexpressing cardiomyocytes. S100A1 overexpression leads to increased SR calcium load by increasing SERCA2a activity and diminishing diastolic SR calcium leak through RyR2 receptor. S100A1 also diminishes NCX activity indirectly by increasing SERCA2a activity, it diminishes cytosolic diastolic calcium levels, thus decreasing calcium extrusion through NCX. Diminished NCX activity decreases intracellular $\mathrm{Na}^{+}$ levels. Also, S100A1 overexpressing cardiomyocytes display lower systolic motility inhibition due to S100A1 effects on titin-actin interaction. Increased SR calcium load combined with increased systolic RyR2 activity increases SR calcium release and EC coupling gain. S100A1 overexpression increases ATP production thus increasing both systolic and diastolic function.

\section{S100A1 effects depend on subcellular localization}

It has been demonstrated that S100A1 has different effects on calcium handling according to its subcellular location (Fig. 2) (Most et al. 2005). 

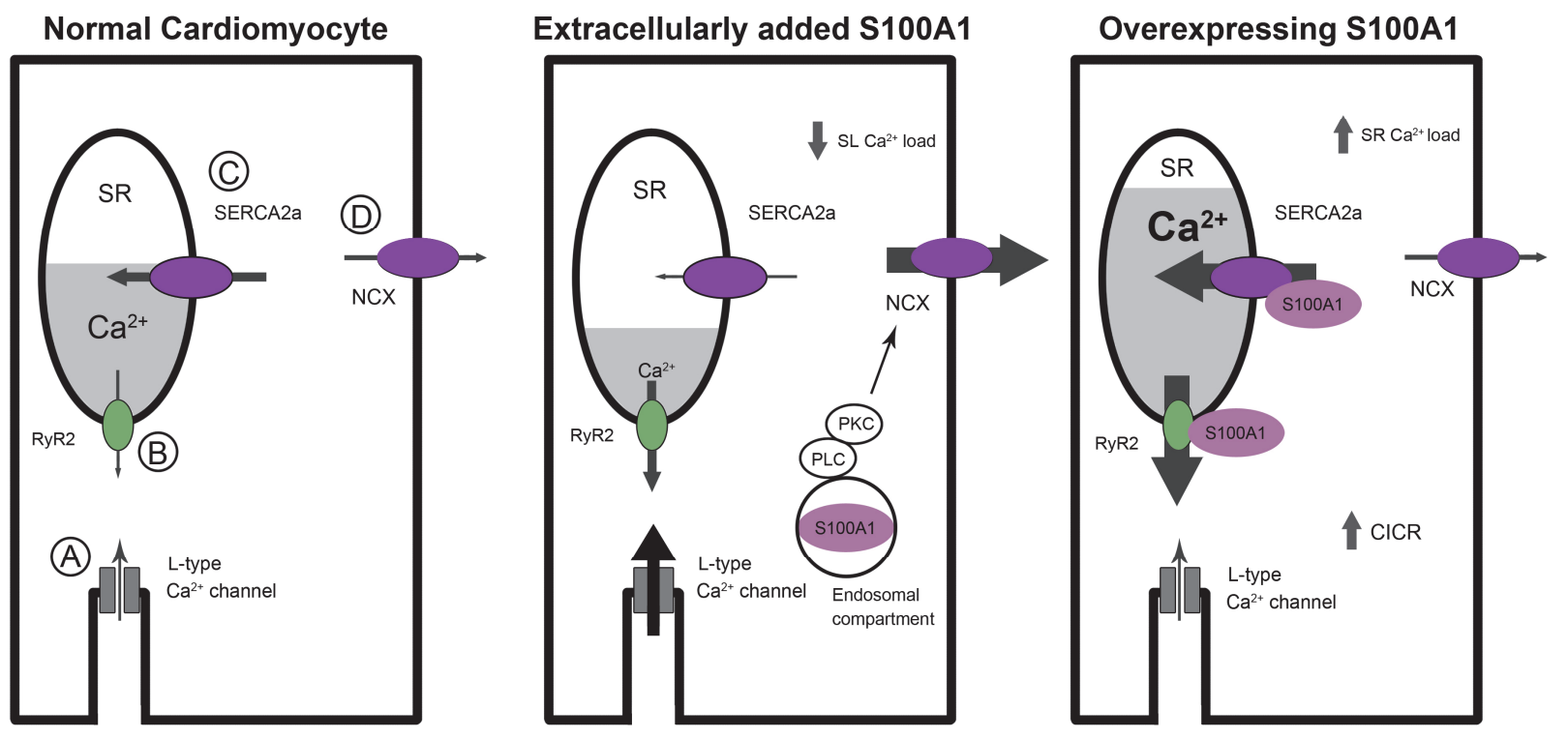

Fig. 2. Differential effects of overexpressing and endocytosed S100A1. Left panel - Simplified scheme of intracellular calcium cycling in normal ventricular cardiomyocyte: A - Electrical depolarization of the T-tubule activates inward calcium flux through L-type calciumchannels. B - Consequently it triggers the release of calcium from SR stores via RyR2. As a result, contraction occurs. C - SERCA2a resequesters cytosolic calcium, lowering its levels and promoting relaxation. D - Sarcolemmal $\mathrm{Na}^{+} / \mathrm{Ca}^{2+}$ exchanger promotes calcium extrusion from the cell. Middle panel - Extracellular S100A1 is targeted to the endosomal compartment, acting through the PLC-PKC pathway enhancing $\mathrm{Na}^{+}$extrusion via NCX. Enhanced calcium extrusion promotes SR calcium depletion. Also, through increased PKA activity, extracellular S100A1 increases L-type calcium channel activity. Right panel - Overexpressed S100A1 localizes to the SR compartment, where it modulates SERCA2a and RyR2 activity. SR calcium cycling is enhanced promoting increase in SR calcium load. This promotes increased calcium induced calcium release (CICR). Adapted with permission from Journal of Cell Science (Most et al. 2005).

S100A1 expressed endogenously or overexpressed by gene therapy, acts predominantly on sarcoplasmic reticulum calcium regulatory proteins (sarcoplasmic reticulum calcium ATPase and ryanodine receptors), mitochondria ( $\mathrm{F}_{1}$-ATPase) and myofilaments (titin).

Experiments with neonatal and embryonic murine cardiomyocytes incubated with S100A1 demonstrate that extracellular S100A1 is endocytosed by clathrin coated vesicles and its effects are most prominent in sarcolemmal calcium regulatory proteins $\left(\mathrm{Na}^{+} / \mathrm{Ca}^{2+}\right.$ exchanger, L-type calcium channels) (Most et al. 2005).

Throughout this review we address endogenous S100A1 as S100A1. In contrast, extracellularly added S100A1 is explicitly referred as extracellular S100A1.

\section{S100A1 interacts with SERCA2a in a calcium-dependent} manner

Decreased levels of sarcoplasmic reticulum calcium ATPase, SERCA2a, mRNA expression and enhanced levels of nitration are characteristic of heart failure (Lokuta et al. 2005). Increased nitration of the protein SERCA2a causes its inactivation (Lokuta et al. 2005) which leads to diminished SR calcium uptake during diastole, increased relaxation time and diminished SR calcium release (Lokuta et al. 2005, Lompre et al.
2010). $\mathrm{G}_{\mathrm{q}}$-protein coupled receptor agonists, like endothelin-1(ET-1) and phenylephrine, seem to upregulate atrial natriuretic peptide (ANP) and downregulate SERCA2a mRNA levels (Most et al. 2006). This may explain, at least in part, why SERCA2a levels are reduced in HF. Decreased SERCA2a-mediated calcium reuptake may contribute to the increase in diastolic calcium levels found in HF given that SERCA2a is a major part of the calcium reabsorption mechanism during relaxation (Birkeland et al. 2005).

S100A1 has been reported to interact with (SERCA2a) and phospholamban (PLB) in a calciumdependent manner (Kiewitz et al. 2003, Pleger et al. 2008). S100A1-based gene therapy demonstrated a nearly 2-fold increase in SERCA2a activity (Brinks et al. 2011). Transgenic mice presented increased expression and diminished nitration of SERCA2a protein. Transgenic mice also showed unaltered SERCA2a expression up to four weeks after myocardial infarction (Kettlewell et al. 2005, Most et al. 2006). Also, nitration levels in transgenic mice were only slightly increased after MI, while S100A1 knockout (SKO) mice showed significantly higher levels of SERCA2a nitration (Most et al. 2006). S100A1-based gene therapy increased SERCA2a-mediated calcium cycling. This is congruent with the reports of in vivo, intracoronary S100A1 gene 
delivery which normalized contractile function of failing myocardium, including $\mathrm{dP} / \mathrm{dt}_{\text {min }}$, a parameter highly dependent on SERCA2a activity (Most et al. 2004).

\section{RyR2 receptor: its biphasic modulation by S100A1}

Cardiac ryanodine receptors (RyR2) are a significant part of the calcium-induced calcium release (CICR) that occurs in normal excitation-contraction coupling (EC coupling). Calcium enters the cell through L-type calcium channels, increases calcium levels near the sarcoplasmic reticulum (SR) and triggers the opening of RyR2 receptors, leading to an even greater calciumrelease from the SR, necessary for contraction to occur (Birkeland et al. 2005).

S100A1 co-localizes with RyR2 receptors improving CICR in S100A1 overexpressing mice (Most et al. 2003). S100A1 modulates both systolic and diastolic activity of ryanodine receptors in a calciumdependent manner (Kettlewell et al. 2005). Indeed, high concentrations of the S100A1 protein $(1 \mu \mathrm{M})$ seem to have opposing effects on RyR2 receptors according to calcium levels (Kraus et al. 2009). This biphasic response was well studied by Most and coworkers. They used cardiac SR vesicle preparations, observing that, at diastolic free calcium concentrations $(150 \mathrm{nM})$, S100A1 reduced $\left[{ }^{3} \mathrm{H}\right]$-ryanodine binding and RyR2 opening probability thus reducing diastolic calcium leaks (Most et al. 2004, Pleger et al. 2011). However, at supradiastolic free calcium concentrations (above $300 \mathrm{nM}$ ), S100A1 enhanced $\left[{ }^{3} \mathrm{H}\right]$-ryanodine binding and RyR2 opening probability, which led to increased RyR2 activity and thus increasing SR calcium release during systole (Most et al. 2004). In contrast, $\left[{ }^{3} \mathrm{H}\right]$-ryanodine binding studies indicate that lower concentration of S100A1 protein $(0.1 \mu \mathrm{M})$ increase RyR2 activity both at low (100 nM) and high $(300 \mathrm{nM})$ calcium concentration (Kettlewell et al. 2005).

This biphasic effect of high concentrations $(1 \mu \mathrm{M})$ of S100A1 protein on RyR2 channels led to the hypothesis that RyR2 has more than one binding site for S100A1 (Volkers et al. 2010). Indeed, this is the case of the ryanodine receptors in skeletal muscle (RyR1) which have at least 3 binding sites for S100A1 (Volkers et al. 2010, Prosser et al. 2011). Further studies are required to determine if the cardiac ryanodine receptor (RyR2) receptor also has multiple binding sites. At least in RyR1, one of the binding sites for S100A1 is the same as the one for calcium-calmodulin (calcium-CaM) complex that is known to be an antagonist of RyR receptors. This binding site is preserved in RyR2 receptor, making it tempting to hypothesize that S100A1 may increase RyR calcium release by competing with calcium-CaM (Wright et al. 2008).

\section{S100A1 effect on L-type calcium channels}

Murine embryonic ventricular cardiomyocytes and neonatal rat cardiomyocytes incubated with S100A1 $(0.001-10 \mu \mathrm{M})$ have demonstrated increased L-type calcium channels (cav 1.2) activity. This effect occurs with the increased activity of the c-AMP dependent protein kinase A (PKA) (Reppel et al. 2005). Endogenously expressed S100A1 does not seem to interact with L-type calcium channels (Kettlewell et al. 2005).

\section{S100A1 interacts with NCX}

The $\mathrm{Na}^{+} / \mathrm{Ca}^{2+}$ exchanger ( $\mathrm{NCX}$ ) is an active mechanism for calcium extrusion of the cell in normal circumstances. It exchanges $3 \mathrm{Na}^{+}$ions into the cell for each calcium ion that leaves the cell (Birkeland et al. 2005).

Neonatal ventricular cardiomyocytes (NVCM) incubated with rhodamine-conjugated S100A1 (Rh-S100A1) exhibit increased $\mathrm{Na}^{+} / \mathrm{Ca}^{2+}$ exchange current (Most et al. 2005). The molecular mechanisms are not well known, but both PKA activity (Reppel et al. 2007) and the phospholipase C (PLC)-PKC pathway (Most et al. 2005) have been suggested as effectors. In contrast, overexpression of S100A1 by gene therapy was reported to diminish NCX mRNA expression in failing cardiomyocytes (Most et al. 2004). Also, endogenous S100A1 may act indirectly by increasing SERCA2a activity which decreases diastolic calcium levels, thus reducing NCX activity.

Increased NCX activity during HF may contribute to the increased $\left(\mathrm{Na}^{+}{ }_{\mathrm{i}}\right)$ observed in failing cardiomyocytes.

\section{S100A1 improves energy homeostasis}

Cardiac function depends not only on calcium homeostasis but also on energy balance. In order to sustain proper cardiac function, cardiomyocyte energy production must strictly correlate with energy expenditure. Calcium has been shown to play a major role in mitochondrial adaptation to energy expenses. It has been reported that $\mathrm{F}_{1} \mathrm{~F}_{0}$-ATPase-dependent ATP synthesis correlates with calcium levels in heart cells 
(Boerries et al. 2007). In HF, there are several indicators of energy starvation such as decreased phosphocreatine/ATP ratio, increased ADP levels and decreased ATP/ADP ratio (Ingwall et al. 2004, VenturaClapier et al. 2004).

Cells treated with adenoviral S100A1 (adS100A1) were found to have higher levels of ATP when compared to control cells expressing only endogenous S100A1 (Wright et al. 2005, Boerries et al. 2007, Brinks et al. 2011). In response to electrical stimulation, adS100A1 cells had an even greater increase in ATP levels compared to control cells.

Pull down assays showed interaction between S100A1 and five mitochondrial proteins: hydroxylcoenzyme A dehydrogenase, $\alpha$ and $\beta$-chain of $F_{1}$-ATPase, isocitrate dehydrogenase 2 , annexin $\mathrm{V}$ and adenine nucleotide translocase.

Western-Blotting analyses revealed that in the presence of EDTA (a calcium chelate) there was no interaction between $\mathrm{S} 100 \mathrm{~A} 1$ and $\mathrm{F}_{1}$-ATPase. The same was observed in pull-down assays when $\mathrm{pH}$ was lower than 6.8 (interaction was verified at a $\mathrm{pH}$ of 7.4). Thus, it is possible to conclude that S100A1 interaction with $\mathrm{F}_{1}$-ATPase is dependent on calcium and physiological $\mathrm{pH}$ levels (Boerries et al. 2007). It was also shown that this interaction led to increased ATP synthesis and higher ATP levels. In fact, S100A1 deficient cardiomyocytes displayed reduced ATP levels, whereas S100A1 overexpressing cells had higher ATP levels. Furthermore, S100A1 deficient cells did not increase ATP levels as effectively as controls when stimulated (Boerries et al. 2007).

Cardiomyocyte relaxation also seems to depend on ATP levels (Volkers et al. 2010). ATP-dependent SERCA2a activity is of major importance to diminish calcium concentration during diastole (Bers 2002). Thus, reduced ATP levels in S100A1 deficiency may help explain the impaired diastolic function in HF (Volkers et al. 2010).

\section{S100A1: a modulator of titin-actin interaction}

Titin is the largest protein found in the human body. It is expressed in different isoforms with molecular weights between 2970 and $3700 \mathrm{kD}$. There are two isoforms of titin in cardiomyocytes, N2B and N2BA, which are obtained by alternative splicing (CastroFerreira et al. 2011). S100A1 protein has been reported to interact with this giant protein at several sites, including the portion of its I-band rich in proline $(P)$, glutamate $(E)$, valine (V) and lysine (K): the PEVK segment (Yamasaki et al. 2001, Castro-Ferreira et al. 2011).

Titin-dependent cardiomyocyte passive tension is determined by both titin's intrinsic elasticity and titinactin interactions. Passive tension, determined by titin intrinsic properties, may be modulated by the N2BA/N2B ratio and titin phosphorylation (Borbely et al. 2009, Castro-Ferreira et al. 2011). There is no evidence indicating that S100A1 modulates these intrinsic properties. However, S100A1 appears to modulate titinactin interactions.

Titin-actin interaction occurs in a particular portion of the titin molecule, the PEVK domain. This interaction seems to delay filament sliding, a mechanism known as viscous break. This effect is important during diastole, providing resistance to stretch. However, during systole, this effect opposes filament sliding, delaying ejection (Fukushima et al. 2010). It is tempting to hypothesize that a physiological mechanism modulates titin-actin interaction. S100A1 may contribute to such modulation.

As mentioned earlier, the PEVK domain is also a binding site for S100A1, which is consistent with the hypothesis that S100A1 modulates titin-actin interaction. In fact, in PEVK fragments incubated with S100A1, this modulation occurs in a calcium-dependent manner. It has been reported that at higher calcium levels, S100A1 frees the actin from titin, reducing the viscous break imposed by the titin-actin interaction. At lower calcium levels, this mechanism is reduced and titin-actin interactions lead to increased passive tension (Yamasaki et al. 2001).

It is hypothesized that this calcium-dependent modulation is important under physiological conditions. The elevated calcium levels observed during systole, would lead to increased S100A1/PEVK interaction which would diminish PEVK-actin dependent motility inhibition, facilitating myocardial contraction (Yamasaki et al. 2001, Fukushima et al. 2010). It can also be hypothesized that decreased levels of S100A1 observed in HF can promote an increase in titin-actin interaction, which contributes to the increased myocardial stiffness observed in a great proportion of HF patients.

\section{S100A1 as a promoter of cardiomyocyte survival}

During ischemic myocardial lesion, S100A1 protein is released into the extracellular space via unknown mechanisms (Kiewitz et al. 2000). This led to the research of cardioprotective effects of extracellular S100A1 (Most et al. 2003). In NVCM, incubation with 
Rh-S100A1 appears to promote cardiomyocyte survival. This protein enters the cell by endocytosis increasing its concentration in the endosomal compartment. This endocytic process has been confirmed to be calciumdependent and caveolin-mediated. The endocytic event is essential to S100A1's cardiac rescuing properties (Most et al. 2003).

In NVCM, incubation with Rh-S100A1 was reported to increase extracellular signal-regulated kinases (ERK) $1 / 2$ phosphorylation leading to their activation. This phosphorylation is not mediated neither by PKA nor calcium. Instead ERK 1/2 phosphorylation is the result of the PLC-PKC-MEK1 pathway activity, confirmed by the fact that S100A1 anti-apoptotic effects were abolished by the use of a MEK1 inhibitor (Most et al. 2003, 2005). As discussed earlier, endogenous S100A1 is co-localized with the SR calcium-regulatory proteins, and it does not seem to have any effect on ERK $1 / 2$ pathway and apoptosis.

It is tempting to conclude that S100A1 deficiency in HF not only diminishes cardiomyocytes' contractility, but also increases the susceptibility of injured cardiomyocytes to apoptosis (Most et al. 2003). S100A1 also promotes cardiomyocyte survival indirectly by reducing the increased wall stress characteristic of HF, which is known to be a potent stimulus for apoptosis (Most et al. 2006).

\section{S100A1 antihypertrophic effects}

S100A1 has been proposed as an antihypertrophic protein. In fact, S100A1 expression shows an inverse relation with cardiomyocyte diameter (Ehlermann et al. 2000).

Abnormal gene expression has been shown to be characteristic of myocardium hypertrophy. In fact, it has been proposed that S100A1 maintains normal adult gene expression in myocardial tissue thus halting hypertrophy. S100A1 downregulation in HF may unblock a fetal genetic program, leading to a hypertrophic response in damaged cardiomyocytes (Tsoporis et al. 2003).

S100A1 has been shown to inhibit PKC phosphorylation of the target protein. Since PKC pathway seems to be involved in cardiac hypertrophy, PKC inhibition may help explain S100A1 antihypertrophic actions (Ehlermann et al. 2000). S100A1 has also been shown to inhibit microtubule polymerization which may delay hypertrophy (Bianchi et al. 1993, Ehlermann et al. 2000). Atrial natriuretic factor (ANF) and $\alpha$-skeletal actin, which are markers of hypertrophy, seem to be normalized by S100A1 overexpression (Most et al. 2003, Pleger et al. 2005).

$\alpha_{1}$-adrenergic agents, angiotensin II (ANGII), peptide growth factor and mechanical stress have been reported to act as hypertrophy stimulators (Tsoporis et al. 2003). S100A1's protective action may also be an indirect consequence of the increased contractile function of S100A1-expressing cells. Normal systolic and diastolic functions are likely to protect cardiomyocytes from signaling of biomechanical overload and maladaptive adrenergic activation, eliminating the most important triggers of cardiac remodeling (Most et al. 2006).

S100A1 increases both systolic and diastolic cardiac function

As mentioned earlier, S100A1 has differential effects according to calcium levels.

During diastole, S100A1 increases SERCA2a activity (Most et al. 2006) by increasing calcium reabsorption in the SR (Most et al. 2001, 2006). In addition, S100A1 reduces RyR2 activity under low calcium conditions, diminishing SR calcium leak (Most et al. 2004). Throughout diastole, S100A1 interacts with both transporters, leading to increased SR calcium load and diminished cytosolic calcium levels (Lompre et al. 2010). S100A1 has also been shown to decrease the sensitivity of myofilaments to calcium (Most et al. 2001). Both diminished diastolic calcium levels and decreased sensitivity of myofilaments to calcium accelerate diastolic relaxation.

During systole, S100A1 increases RyR2 activity (Most et al. 2004). Combined with increased SR calcium load, increased RyR2 activity leads to a greater SR calcium release during systole, thus promoting EC-coupling gain. S100A1 also interacts with titin during systole. Under high calcium levels, S100A1 diminishes titin-actin interaction thus promoting actin motility, improving systolic function (Yamasaki et al. 2001, Fukushima et al. 2010). Moreover, without baseline S100A1 levels, the heart would function at increased passive tension due to an increased titin-actin interaction.

In conclusion, S100A1 modulates SR calcium homeostasis and titin-actin interactions, leading to increased relaxation during diastole and increased contraction during systole. This, along with other factors such as energy homeostasis, cardiomyocyte survival and vessel relaxation, explains, at least in part, the increase in cardiac function observed when S100A1 is overexpressed 
(Most et al. 2003). Although S100A1 modulates calcium homeostasis, S100A1 overexpression in the myocardial muscle does not seem to increase cardiac arrhythmia frequency or have detrimental effects on cardiac conduction systems in vivo (Weber et al. 2014).

\section{Vascular relaxation modulation by $S 100 \mathrm{Al}$}

Several evidences suggest that S100A1 may have a role on vascular function. In fact, mean arterial pressure is increased in S100A1 KO (SKO) mice compared to wild type (WT) and these mice show increased mortality after MI (Desjardins et al. 2009). Moreover, SKO mice were found to respond significantly less to the vasodilatory effect of acetylcholine (Ach) (Pleger et al. 2008, Desjardins et al. 2009) and vasodilation was almost abolished in response to bradykinin (BK) (Pleger et al. 2008). Ach and bradykinin are known to act through endothelial NO synthase (eNOS) activation, increasing NO generation, which has a major role on endothelial smooth muscle cell relaxation. Also, indirect immunofluorescence staining showed S100A1 expression in endothelial cells (Pleger et al. 2008).

eNOS activation by Ach and BK is dependent on intracellular calcium increase. The fact that calcium plays an important role on eNOS activation makes it tempting to assume that S100A1, which has been shown to improve calcium cycling in cardiomyocytes, may have an important role in NO synthesis and therefore, vascular relaxation (Fig. 3) (Fleming et al. 1999).

In a very interesting and elegant study, Pleger et al. (2008) were the first to demonstrate the importance of S100A1 on eNOS activity. Endothelial vasorelaxation induced by acetylcholine was reduced in SKO mice compared with WT. To assess whether this effect was caused by diminished NO synthesis or by reduced sensibility of vascular smooth muscle cells to NO, sodium nitroprusside (SNP), an NO donor, was administered. No significant difference was observed in SNP-induced vasorelaxation between SKO and WT leading to the conclusion that SKO mice have impaired NO generation by eNOS (Pleger et al. 2008). In fact, eNOS expression is unaltered in the normal tissue of SKO mice (Pleger et al. 2008) and may even be increased under ischemic conditions (Most et al. 2013). In fact, in vitro trials demonstrated that S100A1 overexpression increased acetylcholine-induced NO synthesis, suggesting that normalizing S100A1 may promote vasodilation and reduce blood pressure (Pleger et al. 2008).

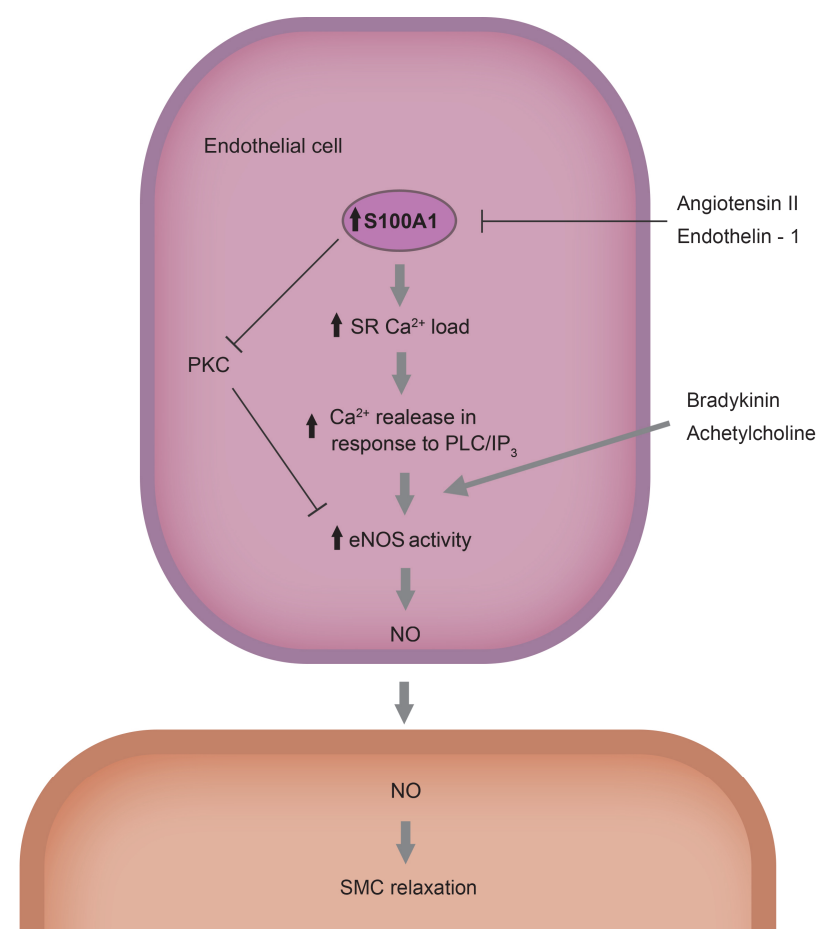

Fig. 3. S100A1 pathway in vessel relaxation. S100A1 increases endothelial SR calcium load, enhancing SR calcium release in response to $\mathrm{IP}_{3}$. Increased endothelial calcium levels increase bradikinin/acetylcholine-induced eNOS activation, increasing NO production. NO, in vascular smooth muscle cells, acts through PKG. NO dephosphorylates the regulatory myosin light chain thus promoting smooth muscle relaxation. Angiotensin II and endothelin-1 have been reported to diminish S100A1 expression, this may be an important mechanism in reducing S100A1 in HF. S100A1 is also an important inhibitor of PKC activity. PKC-mediated phosphorylation of eNOS diminishes its activity. S100A1-induced PKC inhibition may also be important on increasing eNOS activity.

S100A1 KO mice exhibited a significant increase in both systolic and diastolic blood pressure, as well as in mean arterial pressure that may be explained by diminished basal NO release in SKO mice. S100A1 loss has been associated with hypertension in vivo (Pleger et al. 2008), which may partially explain the reduced survival of SKO mice after MI, unveiling the importance of S100A1 in normal endothelial function (Desjardins et al. 2009).

Interestingly, there is evidence that this increase in mean arterial pressure (MAP) in SKO mice was significantly higher in male subjects rather than female subjects. In SKO mice, a higher mortality rate was also observed amongst male subjects (Desjardins et al. 2009).

Both angiotensin II and ET-1 have been shown to decrease S100A1 mRNA expression in endothelial cells (Desjardins et al. 2009). It is tempting to theorize that, in HF, increased levels of ANGII and ET-1 may lead to decreased levels of S100A1 mRNA expression. 
Most et al. (2013) studied the interaction between S100A1 and eNOS in hypoxic endothelial cells. Based on evidence of reduced S100A1 expression in the tissue of patients with critical limb ischemia, the authors studied the potential role of S100A1 on angiogenesis. They compared the vascular regenerative capacity of SKO and WT mice, after femoral artery resection (FAR). SKO mice had compromised reperfusion and neovascularization leading to reduced collateral blood flow after FAR. Insufficient NO production, in response to hypoxia or VEGF, seems to be the pathophysiological basis of this regenerative insufficiency. In fact, NO administration normalized in vivo angiogenesis in SKO mice (Most et al. 2013). By reducing $\mathrm{O}_{2}$ concentration to $2 \%$, the authors demonstrated that mice endothelial cells present reduced levels of S100A1 expression after 24-48 $\mathrm{h}$ exposure to hypoxia. In contrast, shorter $(2 \mathrm{~h})$ exposure to hypoxia demonstrated increased S100A1eNOS interaction. This may represent a short-term adaptive response to hypoxic stress (Most et al. 2013).

PKC phosphorylation of $\operatorname{Thr}(495)$ of eNOS is established as an inhibitory mechanism of eNOS activity (Fleming et al. 2001). Indeed PKC hyperactivation seems to be important in halting eNOS response to VEGF and hypoxia in SKO mice (Most et al. 2013). As mentioned above, S100A1 inhibits PKC activity. So, it is tempting to conclude that S100A1 improves eNOS function not only by increasing intracellular calcium levels but also by inhibiting PKC.

Endothelial dysfunction and impaired vasodilation might therefore contribute to the reduced arterial blood flow recovery in SKO mice since newly formed vessels may be insufficient to provide the necessary blood flow (Most et al. 2013).

\section{Acute versus chronic effects of S100A1}

Under baseline conditions, both S100A1 KO and wild-type mice demonstrated similar heart rates, left ventricular systolic pressures and contraction $\left(\mathrm{dP} / \mathrm{dt}_{\max }\right)$ and relaxation rates $\left(\mathrm{dP} / \mathrm{dt}_{\min }\right)$. Under adrenergic stimulation, S100A1 KO mice were found to have diminished maximal contraction rates, relaxation rates and LV fractional shortening. Also, adrenergic stimulation showed no effect in increasing chronotropism in S100A1 knockout mice. Thus S100A1 seems to be more important in acute stress response than at baseline conditions (Du et al. 2002).

Heterozygous mice also presented diminished inotropism and lusitropism upon adrenergic stimulation, indicating that high levels of S100A1 are required in hemodynamic stress response. They also demonstrated diminished acute response with normal response to chronic pressure overload, which may be explained by compensatory S100A1 upregulation. Heterozygous insufficiency for acute-stress may reflect low-affinity interactions with its target proteins or high levels of effectors (Du et al. 2002).

$100 \mathrm{~A} 1$ seems to increase cardiomyocyte contractile function, improving cardiac function after myocardial infarction (Most et al. 2004). After adenoviral S100A1 gene delivery cardiomyocytes showed both increased baseline function and increased functional reserve in response to acute hemodynamic stress (Pleger et al. 2005). Interestingly S100A1 is released extracellularly a few hours $(2.8 \pm 2.3 \mathrm{~h})$ after myocardial damage (Kiewitz et al. 2000). As explained above, extracellular S100A1 has antiapoptotic actions. So it can be hypothesized that S100A1 may also have acute antiapoptotic actions, promoting survival after myocardial injury.

\section{S100A1 gene therapy and clinical perspectives}

S100A1 genetically targeted therapy has been experimented in several studies throughout the last decade. Both human and rabbit isolated cardiomyocytes (Kettlewell et al. 2005, Brinks et al. 2011) and rat (Most et al. 2004, Pleger et al. 2005, Brinks et al. 2011) and pig (Pleger et al. 2011) in vivo experiments showed increased S100A1 levels in response to genetic therapy. The methodology of S100A1 gene transfer was widely reviewed by Most et al. (2013).

This treatment demonstrated improvement in contractile function in failing cardiomyocytes (FC) when compared to non-treated rats FC (Most et al. 2004, Pleger et al. 2005, Brinks et al. 2011). Increased cardiomyocyte contractility was also observed in vivo, with S100A1treated hearts presenting an increase in $\mathrm{dP} / \mathrm{dt}_{\text {max }}, \mathrm{dP} / \mathrm{dt}_{\text {min }}$ and endsystolic pressures and a decrease in enddiastolic pressures (Pleger et al. 2005, 2007). Also, an adrenergic challenge was better supported by S100A1 treated cardiomyocytes, demonstrating that S100A1 treated cells not only had increased contractility under basal conditions, but also had higher cardiac reserve (Pleger et al. 2005).

Several therapeutic options have been attempted to correct SR calcium cycling in HF. Overexpression of SERCA2a by genetic therapy, phospholamban inhibition or RyR2 activity modulation have been experimented 
(Lompre et al. 2010). Promising results were also obtained by S100A1-based gene therapy in calcium handling. Treated animals displayed increased SERCA2a activity and thus accelerated decay of calcium transients, shown by the reduction of the time constant $\tau$ (tau). As discussed earlier, S100A1 has a biphasic effect on RyR2. S100A1 may contribute to improved calcium transients in S100A1 treated cardiomyocytes by diminishing SR calcium leak during diastole and increasing SR calcium release during systole (Most et al. 2004, Brinks et al. 2011, Pleger et al. 2011). Also, S100A1 treated rat cells showed decreased levels of ANF and NCX mRNA expression when compared to control animals (Most et al. 2004). Intracellular $\mathrm{Na}^{+}$concentrations, which are high in failing cardiomyocytes, have been reported to normalize in S100A1 treated cells (Most et al. 2004, Brinks et al. 2011).

ATP production, which is lower in failing cardiomyocytes, is normalized by adenoviral-S100A1 treatment (Most et al. 2004, Brinks et al. 2011, Pleger et al. 2011). AdS100A1 seems to increase myocardial function by increasing the activity of the remaining cardiomyocytes rather than increasing the number of cardiomyocytes (Pleger et al. 2005). S100A1 promoted regression of the fetal gene expression and diminished LV chamber dilation, ANF levels and the heart weight to body weight ratio (Most et al. 2004, Pleger et al. 2007, Brinks et al. 2011).

Although S100A1 has shown great potential as a treatment for HF, gene therapy requires safe, efficient and reproducible vectors (Pleger et al. 2007). Two major vector types are used: adenoviruses and adenovirus associated vectors. Adenoviruses are vectors with large transgene cloning capacity $(7-8 \mathrm{~kb})$, easily produced and manipulated that show effective myocardial transduction in vivo. They have the disadvantage of frequently presenting inflammatory response in vivo (Vinge et al. 2008). Adenoviral associated vectors (AAV) are more promising in the treatment of chronic diseases since they infect the tissues more rapidly, produce stable, long-term effects and are less immunogenic. On the other hand, they have less transgene cloning capacity $(4-5 \mathrm{~kb})$ (Vinge et al. 2008).

Gene delivery has been limited by the dose of vector needed. The doses used in mice and rats are relatively high. It is not known whether these doses will be sufficient to transfect larger hearts. Also these higher doses required for human HF treatment may not be safe and achievable (Vinge et al. 2008). Immunogenic response is also a problem, the development of low immunogenic AAV is required. The diversity in immunogenic response in each patient may also be a problem (Rohde et al. 2011).

A recent study by Pleger et al. (2011) used gene therapy in HF pigs, which are similar to human hearts in many parameters such as heart rate and the dose needed for gene therapy. Some of these problems seemed to be solved. They demonstrated that, using retrograde coronary venous gene delivery, there were successful results. Besides, the therapy appeared to be safe by several parameters. In porcine experiments, S100A1 gene therapy demonstrated high tissue specificity. Aside from the heart, only skeletal muscle and liver had modest amounts detected. In all other nontarget organs, S100A1 DNA was not detected (Pleger et al. 2011).

S100A1-based gene delivery studies present several limitations. Most studies were made using animal cardiomyocytes. Only one study was made using isolated human cardiomyocytes. Even so, the use of isolated cells could not predict the effects on the whole organ. In addition, the absence of a mechanical load may affect signaling pathways and contractile function. So, although these studies show promising results, further studies in human cardiac tissues are required to better understand the potential of S100A1 as a target in clinical practice (Brinks et al. 2011, Rohde et al. 2011).

\section{Conclusion}

Heart failure constitutes a major health problem in the western world. This syndrome displays high mortality and morbidity rates, requiring improved treatment. The observation that reduced levels of S100A1 are characteristic of HF (Volkers et al. 2010) triggered an extensive research on its molecular interactions and functional importance.

S100A1 improves calcium homeostasis, modulating a myriad of calcium regulatory proteins. This enhancement in calcium cycling may explain the EC-coupling gain and the improvement in both systolic and diastolic cardiac function in overexpressing mice. Besides, S100A1 has been shown to increase ATP production reestablishing normal phosphocreatine (PCr)/ATP and ATP/ADP ratios (Boerries et al. 2007).

S100A1 is an important calcium dependent modulator of titin-actin interaction. In systole, S100A1 diminishes titin-actin interactions, enhancing filament sliding and muscle contraction (Yamasaki et al. 2001). 
During myocardial ischemic lesion, S100A1 is released into the extracellular space. Extracellular S100A1 has been shown to have anti-apoptotic actions. These are mediated by the PLC-PKC-MEK1 pathway, that promotes ERK 1/2 phosphorylation and activation. Phosphorylated ERK $1 / 2$ has anti-apoptotic actions, promoting cell survival (Most et al. 2003, 2005).

S100A1 is an inhibitor of cardiac remodeling and hypertrophy. S100A1 has direct antihypertrophic activity, inhibiting the fetal gene program and microtubule polymerization (Ehlermann et al. 2000, Tsoporis et al. 2003). An indirect mechanism has also been proposed: cardiac function improvement promoted by S100A1 diminishes biomechanical overload and maladaptive adrenergic activation, which are major triggers of cardiac remodeling (Most et al. 2006).

S100A1 effects on endothelial cells have also been reported. S100A1 promotes vessel relaxation, diminishing mean arterial pressure and improving survival in mice. S100A1 probably acts by increasing calcium levels, which promotes eNOS activity and therefore, NO release and SMC relaxation (Desjardins et al. 2009). Increased eNOS activity is also important under hypoxic condition to promote angiogenesis and increase collateral blood flow (Most et al. 2013). Consequently, S100A1 may be a target for future treatment of vascular disorders, such as hypertension, coronary artery disease or limb ischemia.

S100A1 is essential in the acute response to hemodynamic stress. In fact, heterozygous had diminished adrenergic response, compared to wild type. This demonstrates the requirement of high levels of S100A1 to respond to acute adrenergic stimulation (Du et al. 2002, Pleger et al. 2005).

S100A1 has been shown to act on a variety of targets presenting beneficial effects on HF. Some studies have explored the potential of S100A1 gene therapy with encouraging results. Although there is still a long way until this therapy can be used in clinical practice, this is a promising treatment that may rescue cardiac function, reducing mortality and morbidity in HF.

\section{Conflict of Interest}

There is no conflict of interest.

\section{Acknowledgements}

The authors would like to thank Pedro Duarte Costa for his work on figure design. This work was supported by the Portuguese Foundation for Science and Technology Grants PEst-C/SAU/UI0051/2011 and EXCL/BIMMEC/0055/2012 through the Cardiovascular R\&D Unit and by European Commission Grant FP7-Health-2010; MEDIA-261409.

\section{References}

BERS DM: Cardiac excitation-contraction coupling. Nature 415: 198-205, 2002.

BIANCHI R, GIAMBANCO I, DONATO R: S-100 protein, but not calmodulin, binds to the glial fibrillary acidic protein and inhibits its polymerization in a $\mathrm{Ca}(2+)$-dependent manner. J Biol Chem 268: 12669-12674, 1993.

BIRKELAND JA, SEJERSTED OM, TARALDSEN T, SJAASTAD I: EC-coupling in normal and failing hearts. Scand Cardiovasc J 39: 13-23, 2005.

BOERRIES M, MOST P, GLEDHILL JR, WALKER JE, KATUS HA, KOCH WJ, AEBI U, SCHOENENBERGER $\mathrm{CA}$ : $\mathrm{Ca} 2+$-dependent interaction of S100A1 with F1-ATPase leads to an increased ATP content in cardiomyocytes. Mol Cell Biol 27: 4365-4373, 2007.

BORBELY A, FALCAO-PIRES I, VAN HEEREBEEK L, HAMDANI N, EDES I, GAVINA C, LEITE-MOREIRA AF, BRONZWAER JG, PAPP Z, VAN DER VELDEN J, STIENEN GJ, PAULUS WJ: Hypophosphorylation of the Stiff N2B titin isoform raises cardiomyocyte resting tension in failing human myocardium. Circ Res 104: 780-786, 2009.

BRINKS H, ROHDE D, VOELKERS M, QIU G, PLEGER ST, HERZOG N, RABINOWITZ J, RUHPARWAR A, SILVESTRY S, LERCHENMULLER C, MATHER PJ, ECKHART AD, KATUS HA, CARREL T, KOCH WJ, MOST P: S100A1 genetically targeted therapy reverses dysfunction of human failing cardiomyocytes. J Am Coll Cardiol 58: 966-973, 2011.

CASTRO-FERREIRA R, FONTES-CARVALHO R, FALCAO-PIRES I, LEITE-MOREIRA AF: The role of titin in the modulation of cardiac function and its pathophysiological implications. Arq Bras Cardiol 96: 332-339, 2011. 
DESJARDINS JF, POURDJABBAR A, QUAN A, LEONG-POI H, TEICHERT-KULISZEWSKA K, VERMA S, PARKER TG: Lack of S100A1 in mice confers a gender-dependent hypertensive phenotype and increased mortality after myocardial infarction. Am J Physiol Heart Circ Physiol 296: H1457-H1465, 2009.

DROHAT AC, BALDISSERI DM, RUSTANDI RR, WEBER DJ: Solution structure of calcium-bound rat S100B(betabeta) as determined by nuclear magnetic resonance spectroscopy. Biochemistry 37: 2729-2740, 1998.

DU XJ, COLE TJ, TENIS N, GAO XM, KONTGEN F, KEMP BE, HEIERHORST J: Impaired cardiac contractility response to hemodynamic stress in S100A1-deficient mice. Mol Cell Biol 22: 2821-2829, 2002.

EHLERMANN P, REMPPIS A, GUDDAT O, WEIMANN J, SCHNABEL PA, MOTSCH J, HEIZMANN CW, KATUS HA: Right ventricular upregulation of the $\mathrm{Ca}(2+)$ binding protein $\mathrm{S} 100 \mathrm{~A} 1$ in chronic pulmonary hypertension. Biochim Biophys Acta 1500: 249-255, 2000.

FLEMING I, BUSSE R: Signal transduction of eNOS activation. Cardiovasc Res 43: 532-541, 1999.

FLEMING I, FISSLTHALER B, DIMMELER S, KEMP BE, BUSSE R: Phosphorylation of Thr(495) regulates $\mathrm{Ca}(2+) /$ calmodulin-dependent endothelial nitric oxide synthase activity. Circ Res 88: E68-E75, 2001.

FUKUSHIMA H, CHUNG CS, GRANZIER H: Titin-isoform dependence of titin-actin interaction and its regulation by S100A1/Ca2+ in skinned myocardium. J Biomed Biotechnol 2010: 727239, 2010.

HAIMOTO H, KATO K: S100a0 (alpha alpha) protein in cardiac muscle. Isolation from human cardiac muscle and ultrastructural localization. Eur J Biochem 171: 409-415, 1988.

INGWALL JS, WEISS RG: Is the failing heart energy starved? On using chemical energy to support cardiac function. Circ Res 95: 135-145, 2004.

KETTLEWELL S, MOST P, CURRIE S, KOCH WJ, SMITH GL: S100A1 increases the gain of excitation-contraction coupling in isolated rabbit ventricular cardiomyocytes. J Mol Cell Cardiol 39: 900-910, 2005.

KIEWITZ R, ACKLIN C, MINDER E, HUBER PR, SCHAFER BW, HEIZMANN CW: S100A1, a new marker for acute myocardial ischemia. Biochem Biophys Res Commun 274: 865-871, 2000.

KIEWITZ R, ACKLIN C, SCHAFER BW, MACO B, UHRIK B, WUYTACK F, ERNE P, HEIZMANN CW: $\mathrm{Ca} 2+$-dependent interaction of S100A1 with the sarcoplasmic reticulum Ca2+-ATPase2a and phospholamban in the human heart. Biochem Biophys Res Commun 306: 550-557, 2003.

KRAUS C, ROHDE D, WEIDENHAMMER C, QIU G, PLEGER ST, VOELKERS M, BOERRIES M, REMPPIS A, KATUS HA, MOST P: S100A1 in cardiovascular health and disease: closing the gap between basic science and clinical therapy. J Mol Cell Cardiol 47: 445-455, 2009.

LENARCIC ZIVKOVIC M, ZAREBA-KOZIOL M, ZHUKOVA L, POZNANSKI J, ZHUKOV I, WYSLOUCHCIESZYNSKA A: Post-translational S-nitrosylation is an endogenous factor fine tuning the properties of human S100A1 protein. J Biol Chem 287: 40457-40470, 2012.

LOHSE MJ, ENGELHARDT S, ESCHENHAGEN T: What is the role of beta-adrenergic signaling in heart failure? Circ Res 93: 896-906, 2003.

LOKUTA AJ, MAERTZ NA, MEETHAL SV, POTTER KT, KAMP TJ, VALDIVIA HH, HAWORTH RA: Increased nitration of sarcoplasmic reticulum Ca2+-ATPase in human heart failure. Circulation 111: 988-995, 2005.

LOMPRE AM, HAJJAR RJ, HARDING SE, KRANIAS EG, LOHSE MJ, MARKS AR: Ca2+ cycling and new therapeutic approaches for heart failure. Circulation 121: 822-830, 2010.

MARENHOLZ I, HEIZMANN CW, FRITZ G: S100 proteins in mouse and man: from evolution to function and pathology (including an update of the nomenclature). Biochem Biophys Res Commun 322: 1111-1122, 2004.

MOORE BW: A soluble protein characteristic of the nervous system. Biochem Biophys Res Commun 19: 739-744, 1965.

MOST P, BERNOTAT J, EHLERMANN P, PLEGER ST, REPPEL M, BORRIES M, NIROOMAND F, PIESKE B, JANSSEN PM, ESCHENHAGEN T, KARCZEWSKI P, SMITH GL, KOCH WJ, KATUS HA, REMPPIS A: S100A1: a regulator of myocardial contractility. Proc Natl Acad Sci USA 98: 13889-13894, 2001.

MOST P, BOERRIES M, EICHER C, SCHWEDA C, EHLERMANN P, PLEGER ST, LOEFFLER E, KOCH WJ, KATUS HA, SCHOENENBERGER CA, REMPPIS A: Extracellular S100A1 protein inhibits apoptosis in ventricular cardiomyocytes via activation of the extracellular signal-regulated protein kinase 1/2 (ERK1/2). J Biol Chem 278: 48404-48412, 2003. 
MOST P, REMPPIS A, PLEGER ST, LOFFLER E, EHLERMANN P, BERNOTAT J, KLEUSS C, HEIERHORST J, RUIZ P, WITT H, KARCZEWSKI P, MAO L, ROCKMAN HA, DUNCAN SJ, KATUS HA, KOCH WJ: Transgenic overexpression of the Ca2+-binding protein S100A1 in the heart leads to increased in vivo myocardial contractile performance. J Biol Chem 278: 33809-33817, 2003.

MOST P, PLEGER ST, VOLKERS M, HEIDT B, BOERRIES M, WEICHENHAN D, LOFFLER E, JANSSEN PM, ECKHART AD, MARTINI J, WILLIAMS ML, KATUS HA, REMPPIS A, KOCH WJ: Cardiac adenoviral S100A1 gene delivery rescues failing myocardium. J Clin Invest 114: 1550-1563, 2004.

MOST P, BOERRIES M, EICHER C, SCHWEDA C, VOLKERS M, WEDEL T, SOLLNER S, KATUS HA, REMPPIS A, AEBI U, KOCH WJ, SCHOENENBERGER CA: Distinct subcellular location of the Ca2+binding protein S100A1 differentially modulates Ca2+-cycling in ventricular rat cardiomyocytes. $J$ Cell Sci 118: 421-431, 2005.

MOST P, SEIFERT H, GAO E, FUNAKOSHI H, VOLKERS M, HEIERHORST J, REMPPIS A, PLEGER ST, DEGEORGE BR JR, ECKHART AD, FELDMAN AM, KOCH WJ: Cardiac S100A1 protein levels determine contractile performance and propensity toward heart failure after myocardial infarction. Circulation 114: 1258$1268,2006$.

MOST P, LERCHENMULLER C, RENGO G, MAHLMANN A, RITTERHOFF J, ROHDE D, GOODMAN C, BUSCH CJ, LAUBE F, HEISSENBERG J, PLEGER ST, WEISS N, KATUS HA, KOCH WJ, PEPPEL K: S100A1 deficiency impairs postischemic angiogenesis via compromised proangiogenic endothelial cell function and nitric oxide synthase regulation. Circ Res 112: 66-78, 2013.

MOST P, RAAKE P, WEBER C, KATUS HA, PLEGER ST: S100A1 gene therapy in small and large animals. Methods Mol Biol 963: 407-420, 2013.

OTTERBEIN LR, KORDOWSKA J, WITTE-HOFFMANN C, WANG CL, DOMINGUEZ R: Crystal structures of S100A6 in the $\mathrm{Ca}(2+)$-free and $\mathrm{Ca}(2+)$-bound states: the calcium sensor mechanism of $\mathrm{S} 100$ proteins revealed at atomic resolution. Structure 10: 557-567, 2002.

PLEGER ST, REMPPIS A, HEIDT B, VOLKERS M, CHUPRUN JK, KUHN M, ZHOU RH, GAO E, SZABO G, WEICHENHAN D, MULLER OJ, ECKHART AD, KATUS HA, KOCH WJ, MOST P: S100A1 gene therapy preserves in vivo cardiac function after myocardial infarction. Mol Ther 12: 1120-1129, 2005.

PLEGER ST, MOST P, BOUCHER M, SOLTYS S, CHUPRUN JK, PLEGER W, GAO E, DASGUPTA A, RENGO G, REMPPIS A, KATUS HA, ECKHART AD, RABINOWITZ JE, KOCH WJ: Stable myocardial-specific AAV6-S100A1 gene therapy results in chronic functional heart failure rescue. Circulation 115: 2506-2515, 2007.

PLEGER ST, HARRIS DM, SHAN C, VINGE LE, CHUPRUN JK, BERZINS B, PLEGER W, DRUCKMAN C, VOLKERS M, HEIERHORST J, OIE E, REMPPIS A, KATUS HA, SCALIA R, ECKHART AD, KOCH WJ, MOST P: Endothelial S100A1 modulates vascular function via nitric oxide. Circ Res 102: 786-794, 2008.

PLEGER ST, SHAN C, KSIENZYK J, BEKEREDJIAN R, BOEKSTEGERS P, HINKEL R, SCHINKEL S, LEUCHS B, LUDWIG J, QIU G, WEBER C, RAAKE P, KOCH WJ, KATUS HA, MULLER OJ, MOST P: Cardiac AAV9-S100A1 gene therapy rescues post-ischemic heart failure in a preclinical large animal model. Sci Transl Med 3: 92ra64, 2011.

PROSSER BL, HERNANDEZ-OCHOA EO, SCHNEIDER MF: S100A1 and calmodulin regulation of ryanodine receptor in striated muscle. Cell Calcium 50: 323-331, 2011.

REMPPIS A, GRETEN T, SCHAFER BW, HUNZIKER P, ERNE P, KATUS HA, HEIZMANN CW: Altered expression of the $\mathrm{Ca}(2+)$-binding protein S100A1 in human cardiomyopathy. Biochim Biophys Acta 1313: 253-257, 1996.

REPPEL M, SASSE P, PIEKORZ R, TANG M, ROELL W, DUAN Y, KLETKE A, HESCHELER J, NURNBERG B, FLEISCHMANN BK: S100A1 enhances the L-type Ca2+ current in embryonic mouse and neonatal rat ventricular cardiomyocytes. $J$ Biol Chem 280: 36019-36028, 2005.

REPPEL M, FLEISCHMANN BK, REUTER H, PILLEKAMP F, SCHUNKERT H, HESCHELER J: Regulation of $\mathrm{Na}+/ \mathrm{Ca} 2+$ exchange current in the normal and failing heart. Ann NY Acad Sci 1099: 361-372, 2007. 
ROGER VL, GO AS, LLOYD-JONES DM, BENJAMIN EJ, BERRY JD, BORDEN WB, BRAVATA DM, DAI S, FORD ES, FOX CS, FULLERTON HJ, GILLESPIE C, HAILPERN SM, HEIT JA, HOWARD VJ, KISSELA BM, KITTNER SJ, LACKLAND DT, LICHTMAN JH, LISABETH LD, MAKUC DM, MARCUS GM, MARELLI A, MATCHAR DB, MOY CS, MOZAFFARIAN D, MUSSOLINO ME, NICHOL G, PAYNTER NP, SOLIMAN EZ, SORLIE PD, SOTOODEHNIA N, TURAN TN, VIRANI SS, WONG ND, WOO D, TURNER MB, AMERICAN HEART ASSOCIATION STATISTICS C, STROKE STATISTICS S: Heart disease and stroke statistics--2012 update: a report from the American Heart Association. Circulation 125: e2-e220, 2012.

ROHDE D, BRINKS H, RITTERHOFF J, QUI G, REN S, MOST P: S100A1 gene therapy for heart failure: a novel strategy on the verge of clinical trials. J Mol Cell Cardiol 50: 777-784, 2011.

SMITH SP, SHAW GS: A change-in-hand mechanism for S100 signalling. Biochem Cell Biol 76: 324-333, 1998.

TSOPORIS JN, MARKS A, ZIMMER DB, MCMAHON C, PARKER TG: The myocardial protein S100A1 plays a role in the maintenance of normal gene expression in the adult heart. Mol Cell Biochem 242: 27-33, 2003.

VENTURA-CLAPIER R, GARNIER A, VEKSLER V: Energy metabolism in heart failure. J Physiol 555: 1-13, 2004.

VINGE LE, RAAKE PW, KOCH WJ: Gene therapy in heart failure. Circ Res 102: 1458-1470, 2008.

VOLKERS M, ROHDE D, GOODMAN C, MOST P: S100A1: a regulator of striated muscle sarcoplasmic reticulum Ca2+ handling, sarcomeric, and mitochondrial function. J Biomed Biotechnol 2010: 178614, 2010.

WEBER C, NEACSU I, KRAUTZ B, SCHLEGEL P, SAUER S, RAAKE P, RITTERHOFF J, JUNGMANN A, REMPPIS AB, STANGASSINGER M, KOCH WJ, KATUS HA, MULLER OJ, MOST P, PLEGER ST: Therapeutic safety of high myocardial expression levels of the molecular inotrope S100A1 in a preclinical heart failure model. Gene Ther 21: 131-138, 2014.

WRIGHT NT, VARNEY KM, ELLIS KC, MARKOWITZ J, GITTI RK, ZIMMER DB, WEBER DJ: The threedimensional solution structure of $\mathrm{Ca}(2+)$-bound $\mathrm{S100A1}$ as determined by NMR spectroscopy. J Mol Biol 353: 410-426, 2005.

WRIGHT NT, PROSSER BL, VARNEY KM, ZIMMER DB, SCHNEIDER MF, WEBER DJ: S100A1 and calmodulin compete for the same binding site on ryanodine receptor. J Biol Chem 283: 26676-26683, 2008.

WRIGHT NT, CANNON BR, ZIMMER DB, WEBER DJ: S100A1: Structure, function, and therapeutic potential. Curr Chem Biol 3: 138-145, 2009.

YAMASAKI R, BERRI M, WU Y, TROMBITAS K, MCNABB M, KELLERMAYER MS, WITT C, LABEIT D, LABEIT S, GREASER M, GRANZIER H: Titin-actin interaction in mouse myocardium: passive tension modulation and its regulation by calcium/S100A1. Biophys $J$ 81: 2297-2313, 2001. 